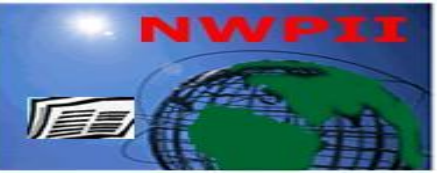

American Journal of Biomedical Sciences

ISSN: 1937-9080

nwpii.com/ajbms

\title{
Soluble Transferrin Receptor Discriminates Iron Deficiency Anemia from Anemia of Chronic Disease in Leukemic and Breast Cancer Patients
}

\author{
${ }^{1}$ Akanni E Olufemi, ${ }^{2}$ Mabayoje V. Olatunji, ${ }^{3}$ Oguntola A. Saliu ${ }^{3}$ Adeoti M. Layiwola, ${ }^{4}$ Adedeji A. \\ Lawrence and ${ }^{5}$ Oparinde D. Pius.
}

${ }^{1}$ Hematology Division, Department of Biomedical Sciences, Ladoke Akintola University of Technology, Osogbo. Nigeria.

${ }^{2}$ Department of Hematology \& Blood Transfusion, Ladoke Akintola University of Technology, Osogbo. Nigeria.

${ }^{3}$ Department of Surgery, Ladoke Akintola University of Technology, Ogbomoso. Nigeria.

${ }^{4}$ Department of Biochemistry, Ladoke Akintola University of Technology, Ogbomoso. Nigeria.

${ }^{5}$ Department of Chemical Pathology, Ladoke Akintola University of Technology, Ogbomoso. Nigeria.

*Corresponding Author

Dr. V.O. Mabayoje

Department of Hematology \& Blood Transfusion

Ladoke Akintola University of Technology

P.M.B. 4400

Osogbo. Nigeria

Tel: +234-803-3294874

E-mail: tunjimabs@yahoo.com

Received: 29 August 2013; $\mid$ Revised: 2 February 2014; | Accepted: 25 February 2014

\begin{abstract}
Anemia is a global public health problem, affecting about $30 \%$ of the world's population. Association of iron deficiency with some chronic diseases is inevitable, hence the necessity to differentiate between anemia of chronic disease and iron deficiency anaemia (IDA). The present study was conducted to discriminate iron deficiency anemia from that due to leukemia and breast cancer as this would help to avoid unnecessary and invasive investigative procedures and also treatment outcomes. Sixty patients drawn from each condition of chronic leukaemia, female breast cancer, other anemic conditions as well as apparently healthy subjects who served as controls were included in the study totalling two hundred and twenty four participants from various clinics of Ladoke Akintola University Teaching Hospital, Osogbo and Abake medical centre Osogbo. Soluble serum transferrin receptor (sTfR) level was determined using Enzyme Linked Immunosorbent Assay (ELISA) with kit from R\&D, Biosystems, UK with the hematocrit determined using the automated method by Sysmex 2006 facility. Serum transferrin receptor level in anemic patients is significantly higher than in control subjects $(p<0.05)$ indicating anemia due to iron deficiency while no significant difference $(p>0.05)$ in sTfR was obtained between breast cancer and control subjects. Leukemia subjects however had a significantly lower sTfR level compared to the control subjects. All the test groups had hematocrit level significantly lower $(\mathrm{p}<0.05)$ than the control group. This study indicates that the anemias observed in breast cancer and leukemia patients are due to anemia of chronic disease (ACD), while anemia in the other anemic
\end{abstract}


patients group is more consistent with iron deficiency anemia. Serum transferrin receptor assay could therefore be a useful non-invasive diagnostic blood test and monitoring and differentiating tool for clinical IDA, and ACD.

Keywords: Soluble serum transferrin receptor, Breast cancer, Leukemia, Anemia, Iron, deficiency, ELISA.

\section{Introduction}

Human transferrin receptor (TfR) is a transmembrane dimeric glycoprotein expressed at the cell surface on nearly all cell types, in particular immature red cells and malignant rapidly proliferating cells [1]. A proteolytic product of intact TfR and a monomeric fragment of the extracellular domain circulates in the plasma as soluble transferrin receptor [1]. Serum levels of the soluble transferrin receptor vary depending on erythropoietic activity and iron status. The concentration of sTfR correlates directly with erythropoietic activity and inversely with the amount of iron available for erythropoiesis [2].

Conventional laboratory indices of iron status such as serum iron, total iron binding capacity (TIBC) and serum ferritin do not always distinguish anaemia of chronic disease (ACD) from iron deficiency anaemia (IDA) as both serum ferritin and transferrin are considerably influenced by acute phase responses in inflammation [1]. Moreover, ACD can coexist with IDA [3]. Therefore to interpret the actual iron status of the patient, a bone marrow examination is the only reliable index of iron stores [4]. Thus there is an evident need for noninvasive and sensitive means for detection of iron deficiency in patients which is not influenced by acute phase reactants or inflammation causing a diagnostic predicament [5].

Measurements of sTfR are useful to investigate the pathophysiology of anemia, because sTfR is a quantitative measure of the rate of erythropoiesis and the adequacy of marrow proliferative capacity for any form of anemia. sTfR can further be used to monitor the erythropoietic response to various forms of therapy, in particular to predict erythroid response before changes in haemoglobin are apparent. Changes in sTfR concentration have consequently been observed in hematologic disorders associated with alterations in erythropoiesis and body iron status [6].

Most anemias are a consequence of either chronic disease (e.g. an inflammatory, infectious or malignant disease) or iron deficiency. The presentation of these two etiologies of anemia is similar, but they can be differentiated by ruling out iron deficiency. The importance of discriminating between IDA and ACD is to be able to provide the best treatment approach in light of the patient's needs. Also, because chronic disease and iron deficiency each affect the traditional laboratory measures of iron status in either the same or opposite directions, there have been no reliable laboratory tests to identify iron deficiency in patients with chronic disease. Soluble serum transferrin is thought to be unchanged in the context of inflammation which could be due to the fact that inflammation reduces the number of erythroid progenitors, so that fewer progenitors making more sTfR ends up looking equal to sTfR in healthy controls [7].

The field lacks sufficient data concerning whether sTfR is appropriate for the discrimination of iron deficiency and cancerrelated anemia. Hence this study is to discriminate iron deficiency anemia from that due to leukemia and breast cancer.

\section{Materials and methods}

\section{Subjects' selection}

A total number of 240 patients who gave their consents were enrolled for the study consisting of 60 apparently healthy individuals in the control group and 60 patients per group for chronic leukaemia, breast cancer and other anaemic patients. Patients in the "other anaemias" group presented with pyrexia of unknown origin (PUO), malaria infections, etc. Patients with sickle cell anemia and pregnant women were excluded. Hematocrit and serum transferrin 
receptor of the patients and control subjects were estimated using automated method by Sysmex facility [9] and ELISA method with the kit from R\&D bio systems, UK respectively.

\section{Specimen collection and storage}

Blood samples were collected from superficial veins in the antecubital fossa into an EDTA anticoagulant tube. Blood samples were centrifuged at $4,000 \mathrm{rpm}$ for 5 minutes with the plasma separated into plain bottles and frozen at minus $20^{\circ} \mathrm{C}$ until analysis. Repeated freeze-thaw cycles were avoided.

\section{Serum transferrin receptor assay technique}

Enzyme Linked Immunosorbent Assay (ELISA) for human sTfR (R\&D systems, UK) was performed according to the manufacturer's instructions.

\section{Statistical Analysis}

The data obtained were statistically analyzed using ANOVA test to compare the data from the breast cancer patients, leukemia, other anemic patients and the control subjects using SPSS software version 16. The results were expressed as mean \pm standard deviation with $\mathrm{p}<0.05$ denoting significant difference between groups.

\section{Results}

Results obtained from this study indicate that serum transferrin receptor level in anemic patients' group is significantly higher than in control subjects $(\mathrm{p}<0.05)$ indicating anemia due to iron deficiency while no significant difference ( $>0.05)$ in sTfR was obtained between breast cancer and control subjects. Leukemia subjects however had a significantly lower sTfR level compared to the control subjects. All the test groups had hematocrit level significantly lower $(\mathrm{p}<0.05)$ than the control group (Table 1).

Comparatively, significant differences $(p<0.05)$ exist between serum transferrin receptors level and hematocrit in breast cancer patients and chronic leukemia in this study (table 2).

Table 1. Serum transferrin receptors concentration and hematocrit levels in the study disease states and control subjects

\begin{tabular}{lll}
\hline Mean \pm SD & $\begin{array}{l}\text { Serum transferrin receptor } \\
\text { STR }(\mu \mathrm{g} / \mathrm{ml})\end{array}$ & $\begin{array}{l}\text { Hematocrit } \\
(\%)\end{array}$ \\
\hline Anemia & $28.05^{*} \pm 8.26$ & $25.65^{*} \pm 7.99$ \\
Breast cancer & $20.86 \pm 7.59$ & $36.50^{*} \pm 4.02$ \\
Leukemia $(\mathrm{CML})$ & $10.40^{*} \pm 3.59$ & $40.50^{*} \pm 2.23$ \\
Control & $19.35 \pm 3.11$ & $43.73 \pm 0.74$ \\
\hline
\end{tabular}

Values are Mean \pm SD; *Significant with control subjects.

Table 2. Comparison of Serum tranferrin receptor and hematocrit of breast cancer and leukemic patients with anemic subjects.

\begin{tabular}{lll}
\hline & Breast cancer & Leukemia (CML) \\
\hline STR & $20.86^{*} \pm 7.59$ & $10.40^{*} \pm 3.59$ \\
PCV & $36.50^{*} \pm 4.02$ & $25.65^{*} \pm 7.99$ \\
\hline
\end{tabular}

Values are Mean \pm SD; $*$ Significant with anemic subjects. 


\section{Discussion and Conclusion}

In this study the soluble serum transferrin receptor level in anemic patients' group (probably due to infections) is significantly higher than in control subjects $(\mathrm{p}<0.05)$ indicating anemia due to iron restricted anemia. This outcome is corroborated with the report of Jayaranee [10] in Singapore on the diagnostic role of soluble serum transferrin receptors in anemias. Their results show that sTfR levels were significantly higher in patients with iron deficiency anemia than in controls and patients with anemia of chronic disease and anemia in chronic renal failure. The increased sTfR could be due to low availability of iron for erythropoiesis as a result of increased need. Reticulocytes entering the peripheral blood stream also carry a high surface concentration of the receptor and as the cells mature the receptors are shed into the circulation. The sTfR in the serum even rises before the haemoglobin concentration is significantly depressed. However there has been no agreement on the source of transferrin receptor as standard or as an antigen for the raising of antibodies [11].

This study also reveals a lower sTfR obtained in leukaemia patients than control subjects though not statistically significant (p>0.05).(Table 1) This finding is also supported by the report of Hanif and colleagues [12] when they investigated the serum transferrin receptor level in iron deficiency and patients with anaemia of chronic disease.

Hematocrit levels (Table 2) were found to be proportional to serum transferrin. This is similar to findings in other studies where there was a positive correlation between the two parameters [13]. This is not unexpected because haematocrit levels are a reflection of iron deficiency anaemia if low, and it has already been established that in IDA serum transferrin levels are increased. In conclusion from the foregoing it can be confidently stated that serum transferrin levels can be a useful parameter in differentiating clinically iron deficient patients from those with anaemia of chronic disease as seen in our patients with breast cancer and leukaemia.

\section{References}

1) Chua E, Clague, A. K, Sharma, M. A (1999). Serum transferrin receptor assay in iron deficiency anaemia and anaemia of chronic disease in the elderly. Q J Med; 92:587-594. DOI: 10.1093 /qimed/92.10.587

2) Skikne B, Flowers CH, Cook JD. (1990). Serum transferrin receptor: a quantitative measure of tissue iron deficiency. Blood ;75:1870-1876.

3) Jain $S$, Narayan $S$, Chandra J, Sharma $S$, Jain S, Malhan P. (2010). Evaluation of serum transferrin receptor and sTfR ferritin indices in diagnosing and differentiating iron deficiency anemia from anemia of chronic disease. Indian J Pediatr. 77(2):179-8. DOI: 10.1007/s12098-009-0302-z

4) van Tellingen A, Kuenen JC, de Kieviet W, van Tinteren H, Kooi ML, Vasmel WL. (2001). Iron deficiency anaemia in hospitalised patients: value of various laboratory parameters. Differentiation between IDA and ACD. Neth J Med.59 (6):270-9. DOI: $10.1016 / \mathrm{S} 0300-$ 2977(01)00169-3

5) Knovich MA, Storey JA, Coffman LG, Torti SV, Torti FM. (2009). Ferritin for the clinician. Blood Rev.;23 (3):95-104. DOI: 10.1016/j.blre.2008.08.001

6) Beguin Y. (2003). Soluble transferrin receptor for the evaluation of erythropoiesis and iron status. Clin Chim Acta.;329 (1-2):922. DOI: $10.1016 /$ S0009-8981(03)00005-6

7) Righetti AA, Wegmüller R, Glinz D, Ouattara M, Adiossan LG, N'Goran EK, Utzinger J, Hurrell RF. (2013). Effects of inflammation and Plasmodium falciparum infection on soluble transferrin receptor and plasma ferritin concentration in different age groups: a prospective longitudinal study in Côte d'Ivoire. Am J Clin Nutr; 97(6):136474. DOI: $10.3945 /$ ajcn.112.050302

8) Suominen P, Punnonen K, Rajamäki A, Irjala K. (1997). Evaluation of new immunoenzymometric assay for measuring soluble transferrin receptor to detect iron 
deficiency in anemic patients. Clin Chem. 43(9):1641-6.

9) Sysmex KX-21N operator's manual. Sysmex Corporation 2006.

10) Jayaranee S, Sthaneshwar P. (2006). Serum soluble transferrin receptor in hypochromic microcytic anaemia. Singapore Med J.47 (2):138-42.

11) Dacie and Lewis. Practical Haematology. Mark Worwood, Alison May.2012. Chapter 9 Eleventh edition. Churchill Livingstone. Pp 175-200.

12) Hanif E, Ayyub M, Anwar M, Ali W, Bashir M. (2005). Evaluation of serum transferrin receptor concentration in diagnosing and differentiating iron deficiency anaemia from anaemia of chronic disorders. J Pak Med Assoc. 55(1):13-6.

13) van Eijk HG, Wiltink WF, Leijnse B. (1975). Haemoglobin levels according to age, haematocrit, transferrin and serum iron level in medical students of comparable socioeconomic status. Folia Haematol Int Mag Klin Morphol Blutforsch. 102(4):448-53. 